\title{
Pengendalian Proses Produksi Makanan Ringan Mini Jelly
}

\author{
Samsudin Hariyanto ${ }^{1^{\star}}$, Digitha Oktaviani Putri ${ }^{2}$, Primahasmi Dalulia ${ }^{3}$ \\ 1,2,3Prodi Teknik Industri,Universitas Merdeka Malang \\ *Korespondensi Penulis, E-mail: samsudin.hariyanto@unmer.ac.id
}

\begin{abstract}
Abstrak
Produk mini jelly, spesifikasi produk yang diperhatikan adalah berat produk atau netto. Berat atau netto produk tersebut merupakan salah satu data variabel yang digunakan dalam pengendalian proses produksi. Untuk memastikan bahwa produk sesuai dengan kualitas yang ditentukan hingga berada di tangan konsumen, maka digunakanlah salah satu metode dalam mengendalikan atau mengolah kualitas yaitu statistical process control. Pengendalian proses produksi makanan ringan mini jelly dapat dianalisis dengan menggunakan peta kendali dan menghitung kapabilitas proses nya. Berdasarkan analisis dengan peta kendali rata-rata dan peta kendali jarak (peta kendali $\mathrm{X}$ dan peta kendali $\mathrm{R}$ ) didapatkan hasil semua data berada dalam batas kendali setelah dua kali revisi karena masih terdapat data yang berada di luar batas kendali pada analisis sebelumnya. Setelah semua data dinyatakan berada pada batas kendali, kemudian dihitung kapabilitas prosesnya. Hasil kapabilitas proses menunjukkan bahwa proses memiliki kapabilitas yang rendah dan kurangnya akurasi proses sehingga diperlukan perbaikan kualitas agar produk yang dihasilkan sesuai dengan spesifikasi yang ditentukan oleh perusahaan dan agar konsumen mendapatkan produk yang berkualitas baik
\end{abstract}

Kata kunci: Mini Jelly, Netto, Kapabilitas Proses.

\section{Pendahuluan}

Jelly merupakan makanan setengah padat yang dibuat dari buah-buahan dan gula dengan kandungan total padatan minimal $65 \%$. Jelly yang baik memiliki tekstur yang kenyal, transparan serta memiliki aroma dan rasa buah yang asli.[1]

Mini Jelly adalah salah satu jenis makanan ringan jelly dengan bentuk cup kecil yang mudah ditemui dan dikonsumsi bagi semua kalangan umur, terutama oleh anakanak. Makanan ringan ini disajikan dari berbagai ukuran dan rasa. Varian yang paling mudah ditemui adalah varian berbagai rasa buah-buahan yang banyak dijual dengan isi sekitar 5-25 cup per kemasannya dengan netto 15 gram per cup. Berat atau netto produk tersebut merupakan salah satu data variabel yang digunakan dalam pengendalian proses produksi. Data variabel merupakan data kuantitatif yang diukur untuk keperluan analisis. [2]

Perusahaan yang memproduksi mini jelly merupakan perusahaan nasional yang memiliki banyak produk olahan berupa jelly, pudding dan nata de coco. Sebagai perusahaan nasional tentulah memastikan bahwa produk sesuai dengan kualitas yang ditentukan hingga berada di tangan konsumen. Salah satu metode dalam mengendalikan atau mengolah kualitas adalah statistical process control yang merupakan suatu teknik untuk memastikan setiap proses yang digunakan agar produk yang dikirimkan kepada konsumen memenuhi standar kualitas. [3] Dari sudut pandang produsen, kualitas dapat diartikan sebagai kesesuaian dengan spesifikasinya. Suatu produk dinyatakan berkualitas oleh produsen apabila produk tersebut telah sesuai dengan spesifikasinya. [4]

Pada produk mini jelly, spesifikasi produk yang diperhatikan adalah berat produk atau netto. Penelitian ini dimaksudkan untuk mengetahui apakah spesifikasi produk yang beredar di pasaran sesuai dengan spesifikasi yang ditetapkan oleh perusahaan dan pengendalian proses produksi. Pengendalian kualitas produk agar mutu atau kualitas produk dapat dijaga, sehingga mampu meningkatkan daya saing.[5] 


\section{Metode Penelitian}

Penelitian ini menggunakan analisis berupa peta kendali dan kemampuan proses. Peta kendali yang digunakan adalah peta kendali rata-rata dan peta kendali jarak (range). Kedua peta kendali tersebut merupakan peta kendali yang dapat memberikan informasi dalam pengambilan keputusan mengenai kualitas proses.

Peta kendali rata-rata merupakan peta pengendali untuk melihat apakah proses masih berada dalam batas pengendalian atau tidak. Peta pengendalian rata-rata menunjukkan apakah rata-rata produk yang dihasilkan sesuai dengan standar pengendalian yang digunakan perusahaan. Sementara itu, peta pengendali jarak (range) digunakan untuk mengetahui tingkat keakurasian atau ketepatan proses yang diukur dengan mencari range dari sampel yang diambil dalam observasi. [6]

Sedangkan kemampuan proses merupakan kemampuan sebuah proses untuk memenuhi spesifikasi desain yang ditetapkan oleh desain rekayasa atau permintaan konsumen. [7]

\section{Hasil dan Pembahasan}

\subsection{Peta Kendali}

Data yang diperoleh pada penelitian ini adalah dari 90 buah mini jelly dengan aneka rasa. Mini jelly tersebut kemudian ditimbang dan dicacat berat nya. Sub grup yang ada pada tabel menunjukkan kode batch produksi yang ada pada kemasan mini jelly. Berikut adalah data yang didapatkan.

Tabel 1. Data Pengamatan Berat Mini Jelly

\begin{tabular}{|c|c|c|c|c|c|}
\hline \multirow{2}{*}{ Pengamatan } & \multicolumn{3}{|c|}{ Berat Netto Mini Jelly (gram) } & \multirow{2}{*}{ Xbar } & \multirow{2}{*}{$\mathrm{R}$} \\
\hline & $\mathrm{X} 1$ & $\mathrm{X} 2$ & X3 & & \\
\hline 1 & 14,4 & 13 & 14 & 13,80 & 1,40 \\
\hline 2 & 14 & 14,2 & 14,2 & 14,13 & 0,20 \\
\hline 3 & 13,7 & 14 & 14 & 13,90 & 0,30 \\
\hline 4 & 13,9 & 14 & 14,1 & 14,00 & 0,20 \\
\hline 5 & 14 & 14,1 & 13,9 & 14,00 & 0,20 \\
\hline 6 & 13,8 & 13,2 & 13,8 & 13,60 & 0,60 \\
\hline 7 & 13,5 & 13,1 & 13,94 & 13,51 & 0,84 \\
\hline 8 & 13,94 & 12,98 & 13,7 & 13,54 & 0,96 \\
\hline 9 & 13,78 & 13,9 & 13,88 & 13,85 & 0,12 \\
\hline 10 & 13,38 & 13,94 & 14,02 & 13,78 & 0,64 \\
\hline 11 & 13,76 & 13,96 & 14,28 & 14,00 & 0,52 \\
\hline 12 & 14,06 & 13,68 & 13,88 & 13,87 & 0,38 \\
\hline 13 & 14,14 & 13,86 & 13,78 & 13,93 & 0,36 \\
\hline 14 & 13,5 & 13,86 & 14,18 & 13,85 & 0,68 \\
\hline 15 & 13,82 & 14,3 & 13,92 & 14,01 & 0,48 \\
\hline 16 & 14,16 & 13,96 & 14,22 & 14,11 & 0,26 \\
\hline 17 & 14,16 & 12,68 & 13,74 & 13,53 & 1,48 \\
\hline 18 & 13,96 & 13,58 & 13,96 & 13,83 & 0,38 \\
\hline 19 & 13,62 & 14,12 & 13,36 & 13,70 & 0,76 \\
\hline 20 & 13,42 & 14 & 13,8 & 13,74 & 0,58 \\
\hline 21 & 13,74 & 13,7 & 13,82 & 13,75 & 0,12 \\
\hline 22 & 13,82 & 13,72 & 13,82 & 13,79 & 0,10 \\
\hline 23 & 13,82 & 13,84 & 13,66 & 13,77 & 0,18 \\
\hline 24 & 13,5 & 11,72 & 13,76 & 12,99 & 2,04 \\
\hline 25 & 13,72 & 13,64 & 13,8 & 13,72 & 0,16 \\
\hline 26 & 13,16 & 13,98 & 13,56 & 13,57 & 0,82 \\
\hline
\end{tabular}




\begin{tabular}{|l|c|c|c|c|c|}
\hline 27 & 14,4 & 14 & 13,96 & 14,12 & 0,44 \\
\hline 28 & 13,9 & 13,82 & 13,7 & 13,81 & 0,20 \\
\hline 29 & 13,84 & 13,6 & 13,7 & 13,71 & 0,24 \\
\hline 30 & 13,78 & 13,4 & 13,46 & 13,55 & 0,38 \\
\hline
\end{tabular}

Dari data pada tabel diatas kemudian dihitung untuk masing-masing peta kendali sebagai berikut:

1. Peta kendali $X$

Rata-rata $X=13,78$

Rata-rata $\mathrm{R}=0,53$

$\mathrm{UCL}=\bar{X}+(A 2 \cdot \bar{R})=13,78+(1,023 \times 0,53)=14,33$

$\mathrm{LCL}=\bar{X}-(A 2 . \bar{R})=13,78-(1,023 \times 0,53)=13,24$

2. Peta Kendali $R$

Rata-rata $\mathrm{R}=0,53$

$\mathrm{UCL}=D 4 \times \bar{R}=2,575 \times 0,53=1,38$

$\mathrm{LCL}=D 3 \times \bar{R}=0 \times 0,53=0$

Sehingga dari perhitungan diatas dapat digambarkan peta kendali $X$ dan $R$ sebagai berikut:

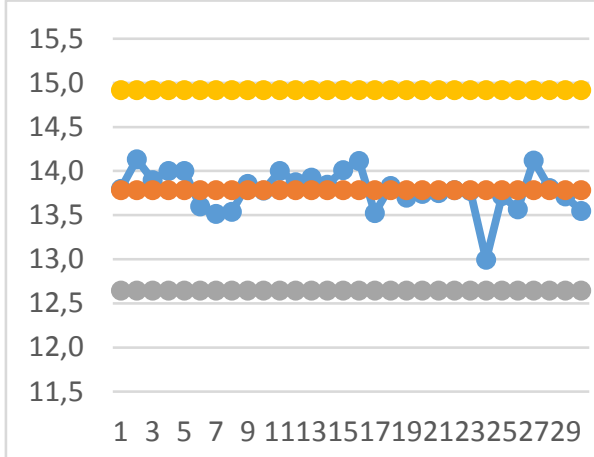

Gambar 1. Peta Kendali X

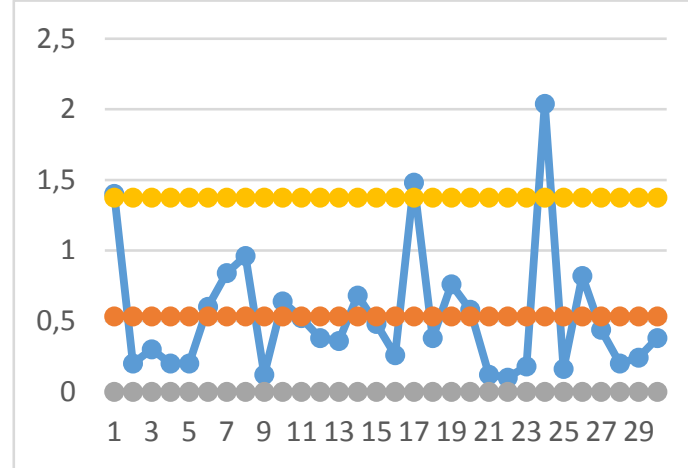

Gambar 2. Peta Kendali R

Berdasarkan gambar diatas terlihat bahwa pada peta kendali $X$ semua data masih berada diantara batas kendali atas dan batas kendali bawah. Namun pada peta kendali $\mathrm{R}$ terlihat bahwa pada data kesatu, ketujuh belas dan keduapuluh empat berada diluar batas kendali atas. Sehingga data tersebut dapat dianggap out of control dan diperlukan revisi.

Setelah dilakukan revisi terhadap data yang out of control, didapatkan hasil sebagai berikut:

Tabel 2. Data Pengamatan Berat Mini Jelly Setelah Revisi

\begin{tabular}{|c|c|c|c|c|c|}
\hline \multirow{2}{*}{ Pengamatan } & \multicolumn{3}{|c|}{ Berat Netto Mini Jelly (gram) } & \multirow{2}{*}{ Xbar } & \multirow{2}{*}{$\mathrm{R}$} \\
\cline { 2 - 4 } & $\mathrm{X} 1$ & $\mathrm{X} 2$ & $\mathrm{X} 3$ & & \\
\hline 1 & 14 & 14,2 & 14,2 & 14,13 & 0,20 \\
\hline 2 & 13,7 & 14 & 14 & 13,90 & 0,30 \\
\hline 3 & 13,9 & 14 & 14,1 & 14,00 & 0,20 \\
\hline 4 & 14 & 14,1 & 13,9 & 14,00 & 0,20 \\
\hline 5 & 13,8 & 13,2 & 13,8 & 13,60 & 0,60 \\
\hline 6 & 13,5 & 13,1 & 13,94 & 13,51 & 0,84 \\
\hline 7 & 13,94 & 12,98 & 13,7 & 13,54 & 0,96 \\
\hline 8 & 13,78 & 13,9 & 13,88 & 13,85 & 0,12 \\
\hline 9 & 13,38 & 13,94 & 14,02 & 13,78 & 0,64 \\
\hline
\end{tabular}




\begin{tabular}{|l|c|c|c|c|c|}
\hline 10 & 13,76 & 13,96 & 14,28 & 14,00 & 0,52 \\
\hline 11 & 14,06 & 13,68 & 13,88 & 13,87 & 0,38 \\
\hline 12 & 14,14 & 13,86 & 13,78 & 13,93 & 0,36 \\
\hline 13 & 13,5 & 13,86 & 14,18 & 13,85 & 0,68 \\
\hline 14 & 13,82 & 14,3 & 13,92 & 14,01 & 0,48 \\
\hline 15 & 14,16 & 13,96 & 14,22 & 14,11 & 0,26 \\
\hline 16 & 13,96 & 13,58 & 13,96 & 13,83 & 0,38 \\
\hline 17 & 13,62 & 14,12 & 13,36 & 13,70 & 0,76 \\
\hline 18 & 13,42 & 14 & 13,8 & 13,74 & 0,58 \\
\hline 19 & 13,74 & 13,7 & 13,82 & 13,75 & 0,12 \\
\hline 20 & 13,82 & 13,72 & 13,82 & 13,79 & 0,10 \\
\hline 21 & 13,82 & 13,84 & 13,66 & 13,77 & 0,18 \\
\hline 22 & 13,72 & 13,64 & 13,8 & 13,72 & 0,16 \\
\hline 23 & 13,16 & 13,98 & 13,56 & 13,57 & 0,82 \\
\hline 24 & 14,4 & 14 & 13,96 & 14,12 & 0,44 \\
\hline 25 & 13,9 & 13,82 & 13,7 & 13,81 & 0,20 \\
\hline 26 & 13,84 & 13,6 & 13,7 & 13,71 & 0,24 \\
\hline 27 & 13,78 & 13,4 & 13,46 & 13,55 & 0,38 \\
\hline
\end{tabular}

Dari data pada tabel diatas kemudian dihitung untuk masing-masing peta kendali sebagai berikut:

1. Peta kendali $X$

Rata-rata $X=13,82$

Rata-rata $\mathrm{R}=0,46$

$\mathrm{UCL}=\bar{X}+(A 2 \cdot \bar{R})=13,82+(1,023 \times 0,46)=14,29$

$\mathrm{LCL}=\bar{X}-(A 2 \cdot \bar{R})=13,82-(1,023 \times 0,46)=13,36$

2. Peta Kendali $R$

Rata-rata $\mathrm{R}=0,46$

$\mathrm{UCL}=D 4 \times \bar{R}=2,575 \times 0,46=1,18$

$\mathrm{LCL}=D 3 \times \bar{R}=0 \times 0,46=0$

Sehingga dari perhitungan diatas dapat digambarkan peta kendali $X$ dan $R$ sebagai berikut:
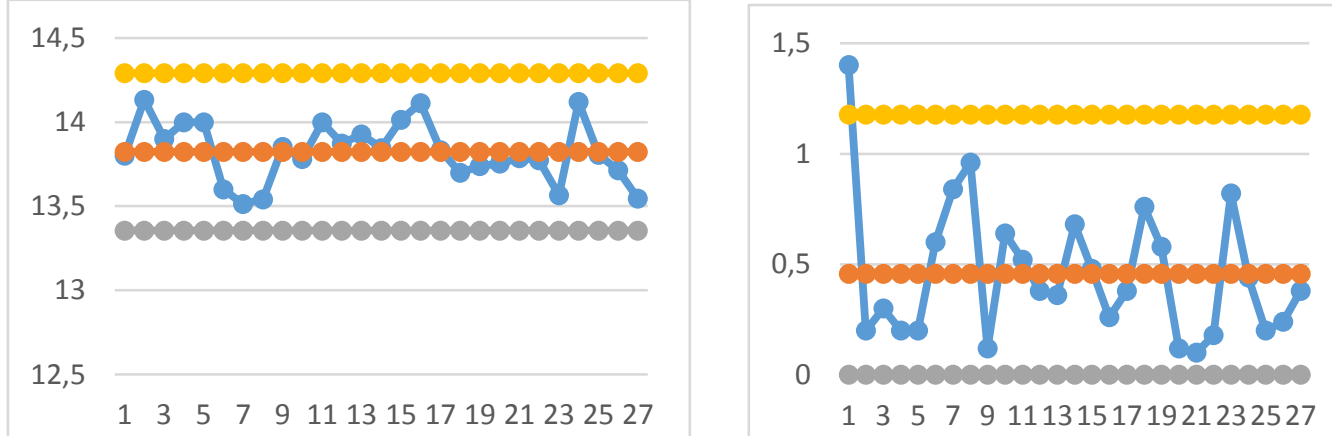

Gambar 4. Peta Kendali X setelah Revisi Gambar 5. Peta Kendali R setelah Revisi

Kedua gambar diatas merupakan peta kendali $\mathrm{X}$ dan $\mathrm{R}$ dengan data yang telah direvisi. Pada peta kendali $X$ didapatkan hasil bahwa seluruh data berada pada batas kendali atas dan batas kendali bawah. Sedangkan pada peta kendali $\mathrm{R}$ masih terdapat data yang keluar dari batas atas yaitu pada data kesatu. Data tersebut dianggap out of 
control sehingga harus dilakukan revisi kembali. Hasil revisi terhadap data tersebut adalah sebagai berikut:

Tabel 3. Data Pengamatan Berat Mini Jelly Setelah Revisi Kedua

\begin{tabular}{|c|c|c|c|c|c|}
\hline \multirow{2}{*}{ Pengamatan } & \multicolumn{3}{|c|}{ Berat Netto Mini Jelly (gram) } & \multirow{2}{*}{ Xbar } & \multirow{2}{*}{$\mathrm{R}$} \\
\hline & $\mathrm{X} 1$ & X2 & X3 & & \\
\hline 1 & 13,7 & 14 & 14 & 13,90 & 0,30 \\
\hline 2 & 13,9 & 14 & 14,1 & 14,00 & 0,20 \\
\hline 3 & 14 & 14,1 & 13,9 & 14,00 & 0,20 \\
\hline 4 & 13,8 & 13,2 & 13,8 & 13,60 & 0,60 \\
\hline 5 & 13,5 & 13,1 & 13,94 & 13,51 & 0,84 \\
\hline 6 & 13,94 & 12,98 & 13,7 & 13,54 & 0,96 \\
\hline 7 & 13,78 & 13,9 & 13,88 & 13,85 & 0,12 \\
\hline 8 & 13,38 & 13,94 & 14,02 & 13,78 & 0,64 \\
\hline 9 & 13,76 & 13,96 & 14,28 & 14,00 & 0,52 \\
\hline 10 & 14,06 & 13,68 & 13,88 & 13,87 & 0,38 \\
\hline 11 & 14,14 & 13,86 & 13,78 & 13,93 & 0,36 \\
\hline 12 & 13,5 & 13,86 & 14,18 & 13,85 & 0,68 \\
\hline 13 & 13,82 & 14,3 & 13,92 & 14,01 & 0,48 \\
\hline 14 & 14,16 & 13,96 & 14,22 & 14,11 & 0,26 \\
\hline 15 & 13,96 & 13,58 & 13,96 & 13,83 & 0,38 \\
\hline 16 & 13,62 & 14,12 & 13,36 & 13,70 & 0,76 \\
\hline 17 & 13,42 & 14 & 13,8 & 13,74 & 0,58 \\
\hline 18 & 13,74 & 13,7 & 13,82 & 13,75 & 0,12 \\
\hline 19 & 13,82 & 13,72 & 13,82 & 13,79 & 0,10 \\
\hline 20 & 13,82 & 13,84 & 13,66 & 13,77 & 0,18 \\
\hline 21 & 13,72 & 13,64 & 13,8 & 13,72 & 0,16 \\
\hline 22 & 13,16 & 13,98 & 13,56 & 13,57 & 0,82 \\
\hline 23 & 14,4 & 14 & 13,96 & 14,12 & 0,44 \\
\hline 24 & 13,9 & 13,82 & 13,7 & 13,81 & 0,20 \\
\hline 25 & 13,84 & 13,6 & 13,7 & 13,71 & 0,24 \\
\hline 26 & 13,78 & 13,4 & 13,46 & 13,55 & 0,38 \\
\hline
\end{tabular}

Dari data pada tabel diatas kemudian dihitung untuk masing-masing peta kendali sebagai berikut:

1. Peta kendali $X$

Rata-rata $X=13,82$

Rata-rata $\mathrm{R}=0,42$

$\mathrm{UCL}=\bar{X}+(A 2 \cdot \bar{R})=13,82+(1,023 \times 0,42)=14,25$

$\mathrm{LCL}=\bar{X}-(A 2 \cdot \bar{R})=13,82-(1,023 \times 0,42)=13,3$

2. Peta Kendali $R$

Rata-rata $\mathrm{R}=0,42$

$\mathrm{UCL}=D 4 \times \bar{R}=2,575 \times 0,42=1,08$

$\mathrm{LCL}=D 3 \times \bar{R}=0 \times 0,42=0$ 
Sehingga peta kendali $\mathrm{X}$ dan peta kendali $\mathrm{R}$ untuk perhitungan tersebut adalah sebagai berikut:
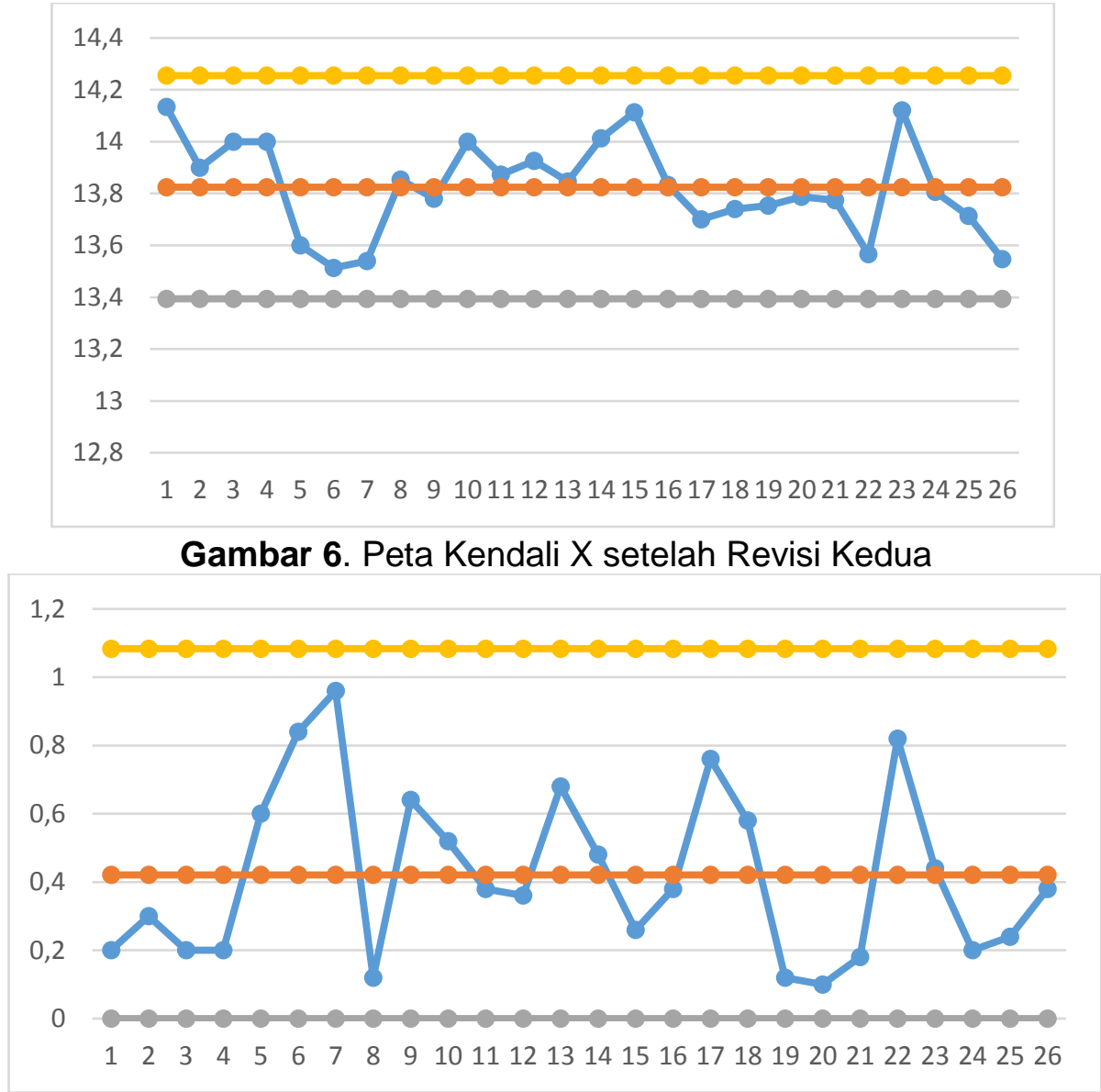

Gambar 7. Peta Kendali R setelah Revisi Kedua

Berdasarkan hasil revisi kedua, didapatkan hasil pada peta kendali $X$ dan peta kendali $R$ masing-masing menunjukkan bahwa seluruh data berada pada batas kendali atas maupun batas kendali bawah. Hal tersebut menunjukkan bahwa keseluruhan data terkendali.

\subsection{Kapabilitas Proses}

Setelah seluruh data dinyatakan telah berada dalam batas kendali, maka langkah selanjutnya dianalisis apakah proses sesuai dengan spesifikasi yang telah ditetapkan. Data yang diambil pada analisis kapabilitas proses ini adalah pada data revisi kedua dimana seluruh data yang telah dianalisis dengan peta kendali $X$ dan peta kendali $\mathrm{R}$ telah berada pada batas kendali. Spesifikasi yang ditetapkan perusahaan adalah yang sesuai dengan netto yang tertulis pada kemasan mini jelly yaitu 15 gram. Sehingga perhitungan analisis kapabilitas proses yang adalah sebagai berikut:

a. $X$ rata-rata $=13,82$

b. $R$ rata-rata $=0,42$

c. Sigma $(\sigma)=\mathrm{R}$ rata-rata: $\mathrm{d} 2=0,42: 1,69=0,24$

d. Indeks kapabilitas proses $\left(\mathrm{C}_{p}\right)$

$$
\begin{aligned}
C_{p} & =\frac{U C L-L C L}{6 \sigma} \\
& =\frac{14,25-13,39}{6 \times 0,24}=0,57
\end{aligned}
$$


Nilai $\mathrm{Cp}$ pada perhitungan diatas adalah 0,57 . Nilai tersebut lebih kecil daripada $1(0,57<1)$, sehingga proses dinyatakan memiliki kapabilitas proses yang rendah dan harus dilakukan perbaikan untuk meningkatkan kapabilitas proses tersebut.

e. Indeks $\mathrm{C}_{\mathrm{pk}}$

$$
\begin{aligned}
\mathrm{CPU} & =\frac{U C L-X}{3 \sigma} \\
& =\frac{14,25-13,82}{3 \times 0,24} \\
& =0,57 \\
\mathrm{CPL} & =\frac{X-L C L}{3 \sigma} \\
& =\frac{13,82-13,39}{3 \times 0,24} \\
& =0,57
\end{aligned}
$$

Maka didapatkan:

$$
\begin{aligned}
& \mathrm{C}_{\mathrm{pk}}=\operatorname{Minimum}(\mathrm{CPU} ; \mathrm{CPL}) \\
& \mathrm{C}_{\mathrm{pk}}=\operatorname{Minimum}(0,57 ; 0,57) \\
& \mathrm{C}_{\mathrm{pk}}=0,57
\end{aligned}
$$

Berdasarkan perhitungan diatas didapatkan nilai $\mathrm{C}_{\mathrm{pk}}$ sebesar 0,57 . Karena $\mathrm{C}_{\mathrm{pk}}<1(0,57<1)$, menunjukkan kurangnya akurasi proses, sehingga proses menghasilkan produk mini jelly yang tidak sesuai dengan spesifikasi.

\section{Kesimpulan}

Pengendalian proses produksi makanan ringan mini jelly dapat dianalisis dengan menggunakan peta kendali dan menghitung kapabilitas proses nya. Berdasarkan analisis dengan peta kendali rata-rata dan peta kendali jarak (peta kendali $\mathrm{X}$ dan peta kendali $\mathrm{R}$ ) didapatkan hasil semua data berada dalam batas kendali setelah dua kali revisi karena masih terdapat data yang berada di luar batas kendali pada analisis sebelumnya. Setelah semua data dinyatakan berada pada batas kendali, kemudian dihitung kapabilitas prosesnya. Hasil kapabilitas proses menunjukkan bahwa proses memiliki kapabilitas yang rendah dan kurangnya akurasi proses sehingga diperlukan perbaikan kualitas agar produk yang dihasilkan sesuai dengan spesifikasi yang ditentukan oleh perusahaan dan agar konsumen mendapatkan produk yang berkualitas baik. Hal tersebut juga menjadikan saran bagi perusahaan agar memperbaiki kualitas proses sehingga kualitas produk terjamin hingga dikonsumsi masyarakat.

\section{Daftar Pustaka}

[1] Koswara, S. (2011). Cara Sederhana Membuat Jam dan Jelly. Ebook Pangan

[2] Gasperz, V. (2010). Total Quality Management: Gramedia Pustaka Utama

[3] Yudianto, Parinduri, L., \& Harahap, B. (2018). Penerapan Metode Statistical Process Control dalam Mengendalikan Kualitas Kertas Bobbin. Buletin Utama Teknik, Vol. 14,No.2.

[4] Devani, V., \& Wahyuni, F. (2016). Pengendalian Kualitas Kertas dengan Menggunakan Statistical Process Control di Paper Machine 3. Jurnal IImiah Teknik Industri , Vol. 15 (2), 87-93. 
[5] R Djoko Andrijono \& Sufiyanto (2019). IbM Bengkel Las Teknik dalam Upaya Peningkatan Kualitas Rectangular Pipe Blending Process dengan Desain Flexible Roll. SENADIMAS UNISRI, 106 - 114

[6] Ariani, W, Dorothea. (2004). Pengendalian Kualitas Statistik: Pendekatan Kuantitatif dalam Manajemen Kualitas. PT. Andi Offset Yogyakarta.

[7] Heizer, J., Render, B., \& Munson,C. (2016) Operations Management. Twelfth Edition. Pearson. 